\title{
Usefulness Assessment of Preoperative MRI Fistulography in Perianal Fistulas Patients
}

\author{
Satish Patil ${ }^{1}$, Shivanand Patil ${ }^{2}$, Vishal Nimbal ${ }^{3}$ \\ ${ }^{1}$ Assistant Professor, ${ }^{2}$ Assistant Professor, ${ }^{3}$ Senior Resident, Department of Radiology, Shri B M Patil Medical College Hospital \\ and Research Centre, Bijapur, Karnataka, India
}

Corresponding author: Dr. Shivanand Patil, Assistant Professor, Department of Radiology, Shri B M Patil Medical College Hospital and Research Centre, Bijapur, Karnataka, India

DOI: 10.21276/ijcmsr.2018.3.3.5

How to cite this article: Satish Patil, Shivanand Patil, Vishal Nimbal. Usefulness Assessment of preoperative MRI fistulography in perianal fistulas patients. International Journal of Contemporary Medicine Surgery and Radiology. 2018;3(3):C21-C24.

\section{A B S T R A C T}

Introduction: Perianal fistulas with a complex, branched and high course, especially in patients after previous surgeries or patients with Crohn disease. Aim: Application of MRI fistulography for evaluation of cases of perianal fistulas difficult to diagnose and treat.

Materials and methods: 31 patients with ano-rectal fistula were enrolled in this study. MRI fistulography findings were analyzed and compared with intraoperative conditions in 31 patients (19 men and 12 women). Imaging was performed with a 1.5-Tesla field strength and a dedicated surface coil placed at the level of hip joints. Contrast agent was a gadolinium-based solution.

Results: $30 \mathrm{MRI}$ fistulographic findings Intraoperatively were consistent with radiological descriptions. According to surgery findings, only one case was a transsphincteric fistula with an abscess in the ischioanal fossa, with an orifice in the posterior crypt, the radiologist described it as a transsphincteric, internal blind fistula.

Conclusion: MRI fistulography becomes a useful and recommended diagnostic method. It point the location of the fistula regarding the system of anal sphincters, and identifies the internal orifice and branching of the fistula. It enables precise planning of surgical treatment.

Key words: Perianal Fistulas, MRI Fistulography, Diagnostic.

\section{INTRODUCTION}

Accurate anatomical mapping of fistulas and potential perirectal suppuration, secondary extensions and relationship to the pelvic floor, sphincters and adjacent perirectal structures is of paramount importance for treatment decisions and planning of surgery. Classification of fistulas relates the primary tract to the sphincter complex, indicating the extent of sphincter division. The risk of subsequent incontinence is greatest when treatment of complex fistulas is inappropriately applied. ${ }^{1}$ Classification therefore determines management, alerting surgeon for the need for staged procedures, perhaps using Seton threads, in an attempt to preserve function where necessary as inadequate or inappropriate fistuloto my can lead to unhealthy ulcers, fecal incontinence and/or need for repetitive complicated surgery. ${ }^{2}$ Previously fistulography, proctoscopy and examination under anesthesia (EUA) were the procedures commonly used for the assessment of perianal fistulas. Currently with the use of endoanal ultrasound (EAUS) and magnetic resonance imaging (MRI) and to a lesser extent, computed tomography (CT). ${ }^{3}$ There is also a group of fistulas with a complex, branched and high course, especially in patients after previous surgeries or patients with Leśniowski-Crohn disease.
Difficulty in the assessing such tracts may lead to unsuccessful "blind" attempts at tract delineation during surgery. These attempts may be followed by formation of a false canal and orifice, and, in consequence, by unnecessarily extensive surgery. Furthermore, "blind" operation favours the formation of pathological granulation tissue - inflammatory foci, while a too aggressive or too conservative operation causes disease recurrence or development of complications such as anal sphincter injury and a faecal incontinence.

Aim: This study was to present own experiences in the application of Magnetic Resonance fistulography in imaging and assessment of perianal fistulas for qualification of patients to surgical procedure.

\section{MATERIAL AND METHODS}

There were 31 patients with perianal fistulas examined (19 men, 12 women), aged greater than 38 years. 6 patients had primary fistulas and 8 patients recurrent fistulas. MRI findings were compared with surgical findings together were used to conclude the case. During operation, 3\% $\mathrm{H} 2$ $\mathrm{O} 2$ and /or methylene blue was introduced into the fistulous tract. It was determined empirically what concentration of paramagnetic gadolinium-based contrast agent should be 
administered into the fistulous tract. To this end, test tubes with a volume of $2 \mathrm{~cm}^{3}$ were filled with $1 \mathrm{~cm}^{3}$ of saline solution, followed by 1, 2, 4, 8, 16, 32 drops of contrast agent added with a 7-0 needle. The most appropriate concentration was found to be two drops of gadolinium added with a 7-0 needle to $1 \mathrm{~cm}^{3}$ of saline.

At the start of MRI examination gadolinium solution was prepared ex tempore and administered in the volume of a few $\mathrm{cm}^{3}$ into the external orifice of the fistulous tract using butterfly cannula without a catheter. Subsequently, the external orifice was covered with plaster dressing with gauze. The examination was performed with a 1.5 Tesla scanner.

\section{STATISTICAL ANALYSIS}

Statistical analysis was done with the help of microsoft office

\begin{tabular}{|l|c|c|}
\hline \multicolumn{3}{|l|}{ Perianal Fistulas } \\
\hline Intersphincteric Fistulas & 10 & $32.2 \%$ \\
\hline Transsphincteric Fistulas & 12 & $38.7 \%$ \\
\hline Suprasphincteric Fistulas & 2 & $6.4 \%$ \\
\hline Extrasphincteric Fistulas & 2 & $6.4 \%$ \\
\hline Multiple Fistulas & 2 & $6.4 \%$ \\
\hline Complex Fistula & 3 & $9.6 \%$ \\
\hline Table-1: Distribution of perianal fistulas according to Park's \\
classification \\
\hline
\end{tabular}
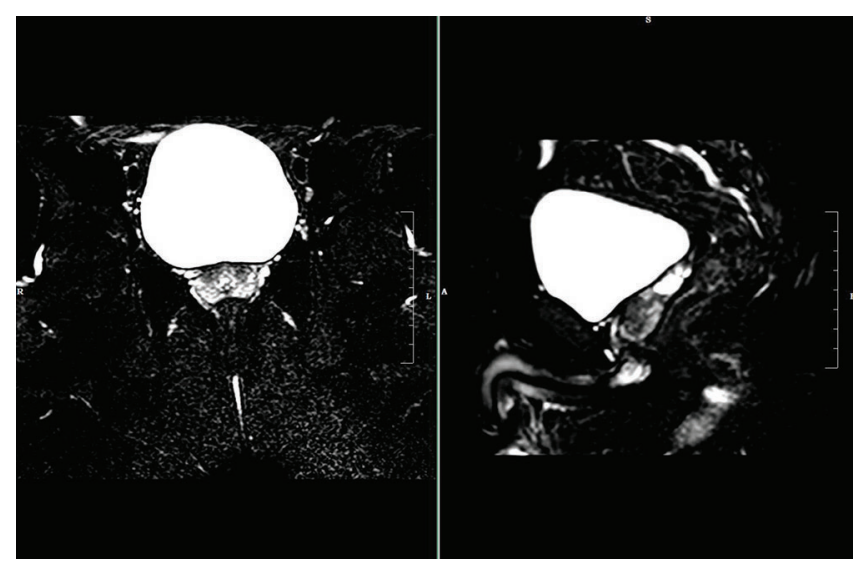

Figure-1: Perianal sinus
2007. Discriptive statistics like mean and percentages were used for the analysis.

\section{RESULTS}

MRI examination showed, according to the Park's classification, 10 intersphincteric, 12 transsphincteric, 2 suprasphincteric and 2 extrasphincteric fistulas. Additionally, 2 fistulas were multiple (with 2 internal orifices), in 3 cases there was a complex fistula, including 2 cases of horseshoe fistula (figure-1).

Transsphincteric Fistulas are more common fistulas seen in study with $38.7 \%$ followed by Intersphincteric Fistulas with $32.2 \%$.

Coronal and Sagittal STIR images (figure-1) show external opening seen at $7 \mathrm{O}$ clock position, which is opening in to a subcutaneous collection measuring about $8-9 \mathrm{~mm}$, this collection is extending supero-medially towards the anal canal for a length of $2 \mathrm{cms}$, to end in the interspincheteric plane. There is no internal opening in to the anal canal seen. No ramifications noted. Ischiorectal fossae are clear.

Two fistulous tracks with enhancing wall, arising from posterior aspect at 7' o clock and 4 'o' clock position on right and left side respectively; hyper intense on T2WI and SPAIR with surrounding inflammatory changes. Both tracks run superiorly with ramifications in perianal fat. Minimal subcutaneous collections seen in the perianal and posterior aspect of gluteal regions (figure-2).

T1 post contrast Axial, SPAIR sagittal and coronal image shows - fistulous track arising from posterior aspect [ $7^{\prime} \mathrm{o}$ clock position] on right side which is hyper intense on $\mathrm{T} 1$ post contrast and SPAIR with surrounding inflammatory changes. Track runs postero superiorly with small secondary track in right perianal fat, traverses into the intersphincteric space and opens obliquely into anus anteriorly [at 11-12' O clock position] approximately $23 \mathrm{~mm}$ above the external anal opening on right side with enhancing peripheral wall seen in intersphincteric plane - suggestive of intersphincteric abscess (figure-3).

\section{DISCUSSION}

Perianal fistulas constitute a heterogenic group of pathologies
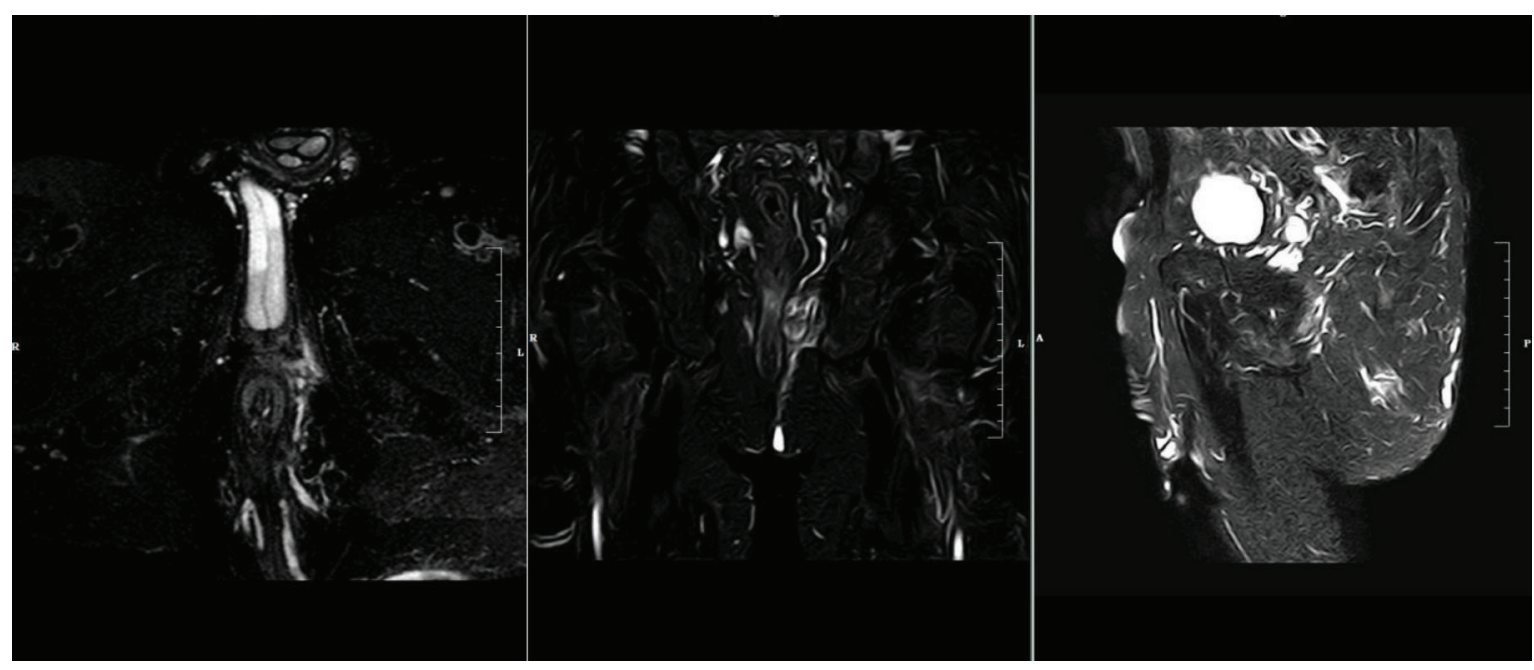

Figure-2: Grade IV Trans-sphincteric fistulae 

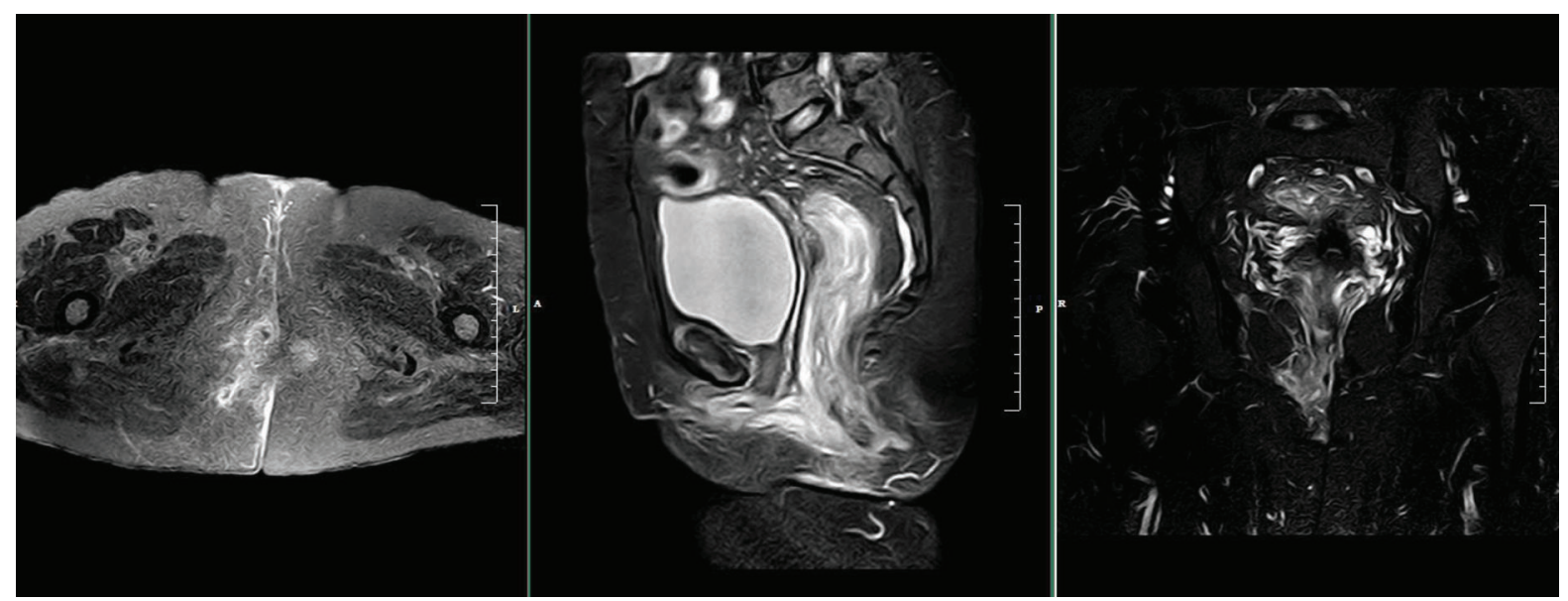

Figure-3: Grade II intersphincteric fistula

of the terminal part of the gastrointestinal tract and perineal area, jointly termed as anorectal malformations. ${ }^{4}$ These are canals filled with granulation tissue and surrounded by thick fibrous tissue. Most of the fistulas are of glandular origin - cryptogenic - and a relatively straight, slightly elliptical tract starting in the perianal area, with the internal orifice in the anal canal, at the level of the crypt. Very rarely fistulas develop in the course of colitis ulcerosa, Leśniowski-Crohn disease, or tuberculosis.

The Park's classification, based on the course of the fistulous tract with regard to the external sphincter of the anus, divides perianal fistulas into four main types: intersphincteric, transsphincteric, suprasphincteric and extrasphincteric. An additional group includes fistulas located superficially, subcutaneously. ${ }^{5}$ Other subtypes of fistulas found in the nomenclature (simple, complex, multiple, high, recurrent) are related to the fistula course, presence of additional canals and openings and type of previous treatment. These factors determine also the method of treatment. In our study, apart from Park's classification, we also used the term 'recurrent fistula', i.e. fistula which developed after previous, unsuccessful surgery, 'complex fistula' (frequently recurrent) located above the puborectalis sling, with branches often directed vertically, upwards and not towards the central part of the anal canal, with internal orifice above the lineapectinata, and 'multiple fistula' (frequently complex) with multiple openings internal and external orifices.

Diagnostics of perianal fistula will be more easy by history-taking and physical examination which should include a detailed anal inspection with a rectal examination. In present study it has helped in correct diagnosis in $48 \%$ of cases. ${ }^{5}$ In total studied population $5 \%$ of fistulas have a difficult diagnosis because of branched, complex course with the tract reaching above the puborectal muscle. Most of the times, the internal orifice is small, narrowed, or periodically closed. Recurrence is will be If the internal orifice has a infected intersphincteric gland which is not removed, and if at all additional canals of the fistula are not found and properly drained or also removed. Symptoms related to the fistula mostly appear after a few days, weeks or months from the time of acute infection - perianal abscess. The most common complains of patients with fistula are: pulsating pain, gradually increasing leakage from a cutaneous orifice - exudative or may be purulent, less often an exudate or pus from the anus, and recurrent symptoms of an abscess. Complains are chronic or recurrent in their nature.

There are three main radiological imaging techniques in perianal fistulas which are useful in the evaluation of the extent of fistula, tissues type involved and presence of additional inflammatory or purulent foci, location of external and internal openings of the fistula, and the course of the main canal and potential additional branches. They include: contrast fistulography, endorectal ultrasonography and magnetic resonance imaging. ${ }^{6-8}$ Each of these methods has some benefits and also disadvantages, as well as limitations; they are used interchangeably in inconclusive cases. Diagnostic tests are extremely helpful in the evaluation of the precise extent of surgical procedure.

Fistulography is least frequently used method which is in visualization of the main canal of the fistula; the sensitivity of that method varies according to different authors, ranges from $24 \%$ to $50 \%$. Additional branches, frequently filled with granulation tissue, are not accessible for a contrast agent administered during that test. ${ }^{9-11}$

The main non-invasive imaging method of parianal fistulas is currently the endoanal ultrasonography (EAUS) and ultrasonography with a contrast agent (3\% hydrogen peroxide), which is becoming more popular and accurate. However, in many cases, EAUS is not able reveal high pathological lesions (suprasphincteric), subcutaneous lesions, of horseshoe type, or smaller additional branches. According to many authors, it may be used only for assessment of postsurgical condition of the sphincters and prior to small surgeries, as incision or drainage. ${ }^{12-14}$

In our study, the type of fistula was identified in all patients on the basis of conducted MR fistulographies, which allowed for an adequate preparation of patients and surgical team prior to surgery. One case of recurrent fistula with an abscess was interpreted as internal blind and trans-sphincteric. Its internal outlet was not visualized which was probably related to an insufficient amount of contrast administered.

In summary, our study lightens that MRI is an necessary and also useful tool in pre-operative diagnosis of the ano-rectal fistula. It provides high resolution images of the anatomy of the ano-rectal region with delicate depiction of the fistulous tracts with their associated secondary ramifications and 
abscesses. Administration of Contrast can provide more information and help in discrimination between active and inactive tracts with delineation of tracts which are not visualized by naked eye.

\section{CONCLUSION}

Exact location of fistulous tract i.e may be internal or external orifice is the main aim of diagnostic in perianal fistulas and also determines the effectiveness of surgery.

MR Fistulography is effective diagnostic in evaluation and assessment of the fistulous path. It helps in locating the fistula in relation to the rectal sphincters and identifies its internal and external orifices as well as additional branches. This improves outcome of patient also help effective planning of surgical treatment.

\section{REFERENCES}

1. Parks AG, Gordon PH, Hardcastle D: A classification of fistula-in-ano. Br J Surg 1976; 63(2):1- 12.

2. Van Beers B, Grandin C, Katheuser A, Hoang P, Mahieu P, Detry R, Vanheuverzwijn R, Pringot J: MRI of complicated anal fistulae: Comparison with digital examination. Comput Assist Tomogr 1994; 18 (4):9499.

3. Garcia-Aguilar J, Belmonte C, Wong D, Goldberg SM, Madoff RD: Anal fistula surgery: Factors associated with recurrence and incontinence. Dis Colon Rectum 1996; 39 (6):723-729.

4. Holschneider A, Hutson J, Pena A, et al. Preliminary report on the International Conference for the Development of Standards for the Treatment of Anorectal Malformations. J Pediatr Surg. 2005; 40 (1):1521-26.

5. Inceoglu R, Gencosmanoglu R. Fistulotomy and drainage of deep postanal space abscess in the treatment of posterior horseshoe fistula. BMC Surgery. 2003; 3 (3):10.

6. Toyonaga T, Tanaka Y, Song IF, et al. Microbiological analysis and endoanal ultrasonography for diagnosis of anal fistula in acute anorectal sepsis. Int J Colorectal Dis. 2006; 22 (5):209-13.

7. Felt-Bersma RJ, Cazemier M. Endosonography in anorectal disease: an overview. Scand J Gastroenterol Suppl. 2006; 243 (4):165-74.

8. Schaefer AO, Baumann T, Langer M. MRI for the detecton of anorectal fistulas. RoFo. 2006;178 (3):1095104

9. Beets-Tan RG, Beets GL, van der Hoop AG, et al. Preoperative MRI of anal fistulas: Does it really help the surgeon? Radiology. 2001; 218 (2):75-84.

10. Kruskal JB, Kane RA, Morrin MM. Peroxide-enhanced anal endosonography: technique, image interpretation and clinical aplications. Radiographics. 2001; 21 (2):173-89.

11. Lunnis PJ, Armstrong P, Barker PG. Magnetic resonance imaging of ananl fistulae. Lancet. 1992; 340 (1):394-96.

12. Maier AG, Funovics MA, Kreuzer SH, et al. Evaluation of perianal sepsis: Comparison of anal endosonography and magnetic resonance imaging. J MagnReson Imaging. 2001; 14 (1):254-60.
13. Sudoł-Szopińska I, Jakubowski W, Szczepkowski M. Contrast-enhanced endosonography for the diagnosis of anal and anovaginal fistulas. J Clin Ultrasound. 2002; 30 (5):145-50.

14. Sangwan YP, Rosen L, Riether RD. Is simple fistula - in - ano simple? Dis Colon Rectum. 1994; 37 (8):885-89.

\section{Source of Support: Nil; Conflict of Interest: None}

Submitted: 18-06-2018; Accepted: 20-07-2018; Published online: 31-07-2018 